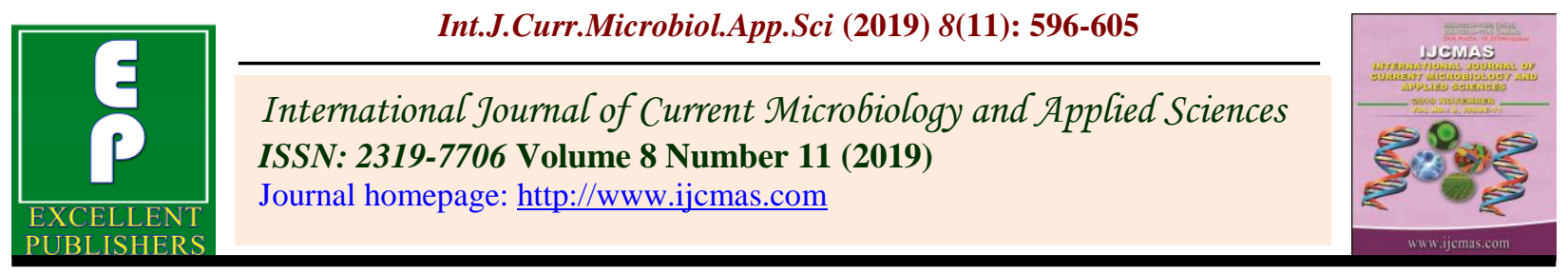

Original Research Article https://doi.org/10.20546/ijcmas.2019.811.073

\title{
Management of Fusarium Wilt of Pigeonpea by Selected Essential Oils and T. viride
}

\author{
Kondakari Mahanthi*, Shashi Tiwari and Amrita Subhadarshini \\ Department of Plant Pathology, Naini Agriculture institute, Sam Higginbottom University of \\ Agriculture, Technology and Sciences, Prayagraj, India \\ *Corresponding author
}

\begin{tabular}{l} 
Ke y w or d s \\
Pigeonpea, Neem \\
oil, Eucalyptus oil, \\
Castor oil, \\
Trichoderma viride \\
\hline Article Info \\
$\begin{array}{l}\text { Accepted: } \\
\text { 07 October } 2019 \\
\text { Available Online: } \\
10 \text { November } 2019\end{array}$ \\
\hline
\end{tabular}

\section{A B S T R A C T}

The antifungal effects of few selected essential oils and Trichoderma viride have been investigated in vivo conditions against Fusarium udum, the causal agent of Fusarium wilt of Pigeonpea. The treatments included Eucalyptus oil, Neem oil, Castor oil, Trichoderma viride each at 5\% and other treatments were each of selected essential oils 5\% in combination with Trichoderma viride 5\% concentration. The treatment was given as seed treatment. An untreated replication served as control. Among the tested treatments, least incidence of disease was seen in plants treated with Castor oil +Trichoderma viride (22\%) followed by Neem oil $+T$. viride (25\%), Eucalyptus oil + Trichoderma viride $(30.33 \%)$. The remaining plants were considerably more affected. Similarly the treatments also had shown good effects on plant growth parameters (height and number of branches). The average height readings of plants was recorded highest in Castor oil + Trichoderma viride $(156.30 \mathrm{~cm})$ followed by Neem oil + Trichoderma viride $(150.16 \mathrm{~cm})$, Eucalyptus oil +Trichoderma viride $(144.90 \mathrm{~cm})$.

\section{Introduction}

Pulses popularly known as "Poor man's meat" and "Rich man's vegetable" are the important source of protein, vitamins, minerals as well as essential amino acid content contributes significantly to the nutritional security of the world (Singh et al., 2015). Among pulses, Pigeonpea [Cajanus cajan L. Millsp.] is second most important pulse in India only after Chick pea. Pigeonpea is adiploid $(2 \mathrm{n}=$ 22). India ranks first in its production and contributes to $90 \%$ of global Pigeonpea (Mespogu et al., 2012).

It is the most important Kharif pulse crop and is popular among the Indian farmers especially in view with its suitability under dry land conditions and its adaptability in mixed/inter cropping systems. It also improves soil 
fertility through nitrogen fixation as well as from the leaf fall and recycling of the nutrients.

Pigeonpea is affected by wide range of diseases by many agents among which Fusarium wilt caused by Fusarium udum is most important as it can cause up to $90 \%$ of losses in case of severe infection (Datta et al., 2013). Plants usually show wilt symptoms around 4-6 weeks after sowing. The primary symptoms are loss of turgidity in leaves and slight inter vein clearing. The foliage shows slight chlorosis and sometimes becomes bright yellow before wilting. The wilting is seen all of a sudden that includes drooping of leaves. The characteristic internal symptom of wilt is the browning of the xylem vessels from the root system to the stems. Cross or longitudinal sections of the wilted plants show brown to black discoloration of xylem vessels. Fusarium is typically facultative saprophytic in nature and can survive as mycelium and chalmydospores in seed, soil or infected crop residues, buried in the soil for upto 5-6 years (Haware et al., 1982).

Among beneficial biological agents, Trichoderma viride, is a filamentous fungi which have attracted attention because of their multi prong action against various plant pathogens (Harman et al., 2004). Trichoderma viride is considered to be one of the most promising microbes for biological control for possessing different mechanisms of action against plant pathology. It shows the inhibitory activities and antagonistic effect against the fungus (Naglot et al., 2015). In Neem oil, salanin and nimbin are the major active potential bioactive compounds. It is compatible and can reduce disease incidence with Trichderma viride (Bagwan, 2010). The major constituents of Eucalyptus oil are monoterpene $\alpha$-pinene $(73.0 \%), \quad p$-cymene $(54.2 \%)$ and $y$-terpinene $(43.8 \%)$. It has the anti-microbial effect and highest growth inhibition capacity (Sartorelli et al., 2007). Castor oil mainly consists of Ricinolic acid (85-95\%) that has good anti-bacterial and antifungal activity (Javaid et al., 2015). Considering these properties of above mentioned oils and biological agent, they are taken up to check their efficacy in management of Fusarium udum causing wilt in Pigeonpea.

\section{Materials and Methods}

\section{Study site}

The present study was carried out in the Department of plant pathology site located at central field of SHUATS, Prayagraj, Uttar Pradesh, during 2018. The experiment was done during kharif season using Randomized Block Design having 8 treatments including a control and 3 replications each with a plot size of $2 \times 2 \mathrm{~m}$.

\section{Seed treatment}

Pigeonpea seeds were taken in separate conical flasks and then three types of essential oils viz., Neem oil, Castor oil, Eucalyptus oil and one bio-agent viz. Trichoderma viride were taken in 5\% concentrations accordingly and poured. For combinations, oil and $T$. viride were taken $5 \%$ each. The flasks were shaken by hand for 5 minutes until the seeds were saturated. In control, seeds were planted with no treatments (Hashem et al., 2010).

\section{Isolation of pathogen}

The pathogen Fusarium udum was isolated from the infected Pigeonpea plants showing typical symptoms of the disease (Fig. 2). The part of collar or stem region showing typical symptoms of the disease was cut into small pieces. These pieces were surface sterilized with $0.1 \%$ mercuric chloride solution for 30 seconds. These were then washed thoroughly 
in sterile water thrice to remove traces of mercuric chloride and then transferred aseptically to sterilized potato dextrose agar (PDA) plates. They were incubated at $27 \pm 1^{\circ} \mathrm{C}$ and checked on 24 hour basis for the growth of the fungus. Later, the bit of fungal growth was transferred to PDA slants. The pure culture of the fungus was obtained by further growing the culture and following hyphal tip culture under aseptic conditions (Rangaswamy, 1972). The pathogen was confirmed by observing the morphological features of colony and spore characteristics (Fig. 1).

\section{Results and Discussion}

Evaluation of different treatments on plant growth parameters of Pigeonpea

The readings for plant growth parameters include height and numbers of branches were taken on 30, 60 and 90 DAS. It was observed that plant growth parameters were good with treatments in combination with Trichoderma viride rather than individually. The essential oils have some antifungal properties, so the treatments showed their action in the in vivo experiment. In the present experiment the combination of essential oil and $T$. viride proved to be more effective than the single treatment. The experiment showed that $\mathrm{T}_{7}$ Castor oil $+T$. viride gave the best result in turns of height, maximum number of branches and also give maximum inhibition of pathogen. At 90 DAS, the data showed maximum height of $156.30 \mathrm{~cm}$ and 14.33 branches in $T_{7}$ treatment followed by $T_{5}$ height of $150.16 \mathrm{~cm}$ and 13.66 branches, $\mathrm{T}_{6}$ height of $144.90 \mathrm{~cm}$ and 13 branches (Fig. 3 and Table 1).

Similar findings were given by Zote et al., (2007) who studied the management of wilt (F. oxysporum f.sp. ciceri) of Chickpea (Cicer arietinum) by integrating a biological control agent $T$. viride, three fungicides (Thiram, Carbendazim and Captan) and four oil cakes (Groundnut, Cotton, Neem and Castor bean). However, soil/seed application of $T$. viride was the most effective recording the lowest wilt incidence (19.04 to $33.33 \%)$ and maximum seed germination (86.73 to $90.00 \%$ ) followed by soil application of oil cakes Neem and Castor bean, which recorded 86.60 and $85.40 \%$ seed germination and 38.09 and $47.60 \%$ wilt incidence and 61.91 and $52.40 \%$ wilt reduction, respectively.

\section{Evaluation of different treatments on plant disease incidence}

The data for disease incidence was also parallely taken with growth parameters at 30, 60 and 90 DAS. Similarly, the essential oils in combination of $T$. viride yielded higher inhibitory effect on disease incidence (Fig. 4 and Table 2).

The data of 90 DAS shows the maximum reduction of disease incidence being recorded in treatment $\mathrm{T}_{7}$ Castor oil +Trichoderma viride (22\%) followed by $\mathrm{T}_{5}$ Neem oil +Trichoderma viride $(25 \%)$ followed by the $\mathrm{T}_{6}$ Eucalyptus oil +Trichoderma viride (30.33\%), $\mathrm{T}_{1}$ Trichoderma viride (33.33\%), $\mathrm{T}_{2}$ Neem oil (38.66\%), $\mathrm{T}_{3}$ Eucalyptus oil $(39 \%)$ and $\mathrm{T}_{4}$ Castor oil $(55 \%)$, while $\mathrm{T}_{0}$ Control had the maximum disease incidence i.e. $70 \%$.

Zote et al., (2007) who studied the management of wilt ( $F$. oxysporum f.sp. ciceri) of Chickpea (Cicer arietinum) by integrating a biological control agent $T$. viride, three fungicides (Thiram, Carbendazim and Captan) and four oil cakes (groundnut, cotton, neem and castor bean).

However, soil/seed application of $T$. viride was the most effective recording the lowest wilt incidence (19.04 to $33.33 \%)$ and maximum seed germination ( 86.73 to $90.00 \%$ ) 
followed by soil application of oil cakes neem and castor bean, which recorded 86.60 and $85.40 \%$ seed germination and 38.09 and $47.60 \%$ wilt incidence and 61.91 and $52.40 \%$ wilt reduction, respectively. Jaiswal et al.,
(2015) who landed an experiment against Fusarium oxysporum f. Sp. lycopersici (FOL) which is a highly destructive pathogen in both green house and field conditions.

Table.1 Effect of treatments on plant growth

\begin{tabular}{|c|c|c|c|c|c|c|}
\hline \multirow[t]{2}{*}{ Treatments } & \multicolumn{2}{|c|}{30 DAS } & \multicolumn{2}{|c|}{60 DAS } & \multicolumn{2}{|c|}{90 DAS } \\
\hline & Height & Branches & Height & Branches & Height & Branches \\
\hline $\operatorname{Control}\left(\mathbf{T}_{0}\right)$ & 17.33 & 1 & 77.01 & 4 & 115.03 & 7.33 \\
\hline Trichoderma viride $\left(\mathrm{T}_{1}\right)$ & 22.96 & 3 & 102.46 & 6.66 & 132.93 & 12.33 \\
\hline Neem oil $\left(T_{2}\right)$ & 22.13 & 2.66 & 96.73 & 5.66 & 127.90 & 11.33 \\
\hline Eucalyptus oil $\left(\mathbf{T}_{\mathbf{3}}\right)$ & 21 & 2 & 93.96 & 5.33 & 125.10 & 10.66 \\
\hline Castor oil $\left(\mathbf{T}_{4}\right)$ & 20.66 & 1.66 & 92.10 & 4.33 & 118.66 & 8.66 \\
\hline Neem oil $+T$. viride $\left(\mathrm{T}_{5}\right)$ & 25 & 3.66 & 116.01 & 8 & 150.16 & 13.66 \\
\hline $\begin{array}{c}\text { Eucalyptus oil+T.viride } \\
\left(\mathrm{T}_{6}\right)\end{array}$ & 23.66 & 3.33 & 107.93 & 7.33 & 144.90 & 13 \\
\hline Castor oil $+T$. viride $\left(\mathrm{T}_{7}\right)$ & 26 & 4 & 124.23 & 8.33 & 156.30 & 14.33 \\
\hline F test & $\mathbf{S}$ & $\mathbf{S}$ & $\mathbf{S}$ & $\mathbf{S}$ & $\mathbf{S}$ & $\mathbf{S}$ \\
\hline SEd(+) & 1.824 & 0.489 & 0.489 & 0.6713 & 0.6713 & 0.549 \\
\hline CD (0.05) & 3.916 & 1.053 & 1.053 & 1.433 & 1.433 & 1.179 \\
\hline
\end{tabular}

Table.2 Effects of treatments on disease incidence of Pigeonpea

\begin{tabular}{|c|c|c|c|}
\hline Treatments & 30 DAS & 60 DAS & 90 DAS \\
\hline $\mathbf{T}_{\mathbf{0}}$ & $25 \%$ & $48.66 \%$ & $70 \%$ \\
\hline $\mathbf{T}_{\mathbf{1}}$ & $12.33 \%$ & $21.66 \%$ & $33.33 \%$ \\
\hline $\mathbf{T}_{\mathbf{2}}$ & $12.66 \%$ & $23.33 \%$ & $38.66 \%$ \\
\hline $\mathbf{T}_{\mathbf{3}}$ & $14.33 \%$ & $24.66 \%$ & $39 \%$ \\
\hline $\mathbf{T}_{\mathbf{4}}$ & $21 \%$ & $32 \%$ & $55 \%$ \\
\hline $\mathbf{T}_{\mathbf{5}}$ & $9 \%$ & $15 \%$ & $25 \%$ \\
\hline $\mathbf{T}_{\mathbf{6}}$ & $12.33 \%$ & $21 \%$ & $30.33 \%$ \\
\hline $\mathbf{T}_{\mathbf{7}}$ & $\mathbf{6 . 6 6 \%}$ & $\mathbf{1 2 \%}$ & $\mathbf{2 2 \%}$ \\
\hline $\mathbf{F}$ test & $\mathbf{S}$ & $\mathbf{S}$ & $\mathbf{S}$ \\
\hline $\mathbf{S E . d}( \pm)$ & $\mathbf{1 . 2 9}$ & $\mathbf{1 . 3 9}$ & $\mathbf{3 . 1 5}$ \\
\hline $\mathbf{C D}(\mathbf{0 . 0 5})$ & $\mathbf{2 . 7 6 1}$ & $\mathbf{1 . 7 2 1}$ & $\mathbf{3 . 9 0 8}$ \\
\hline
\end{tabular}


Fig.1 Microscopic view of F. udum

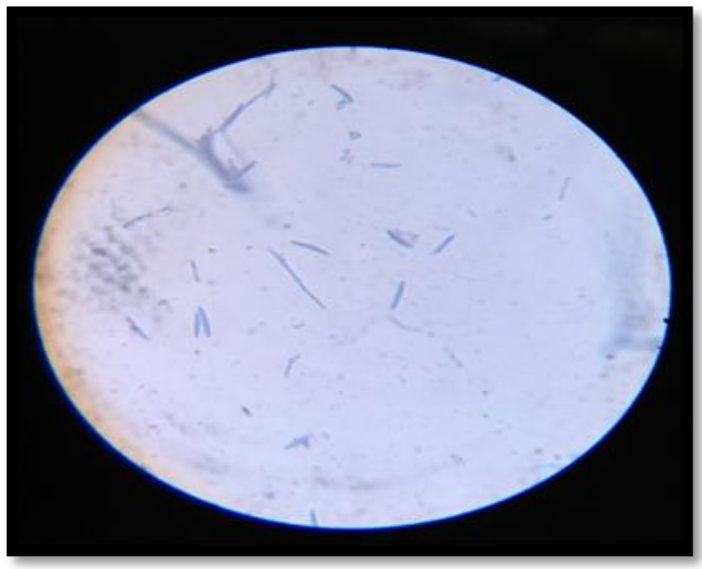

Fig.2 Plant affected by $F$. udum

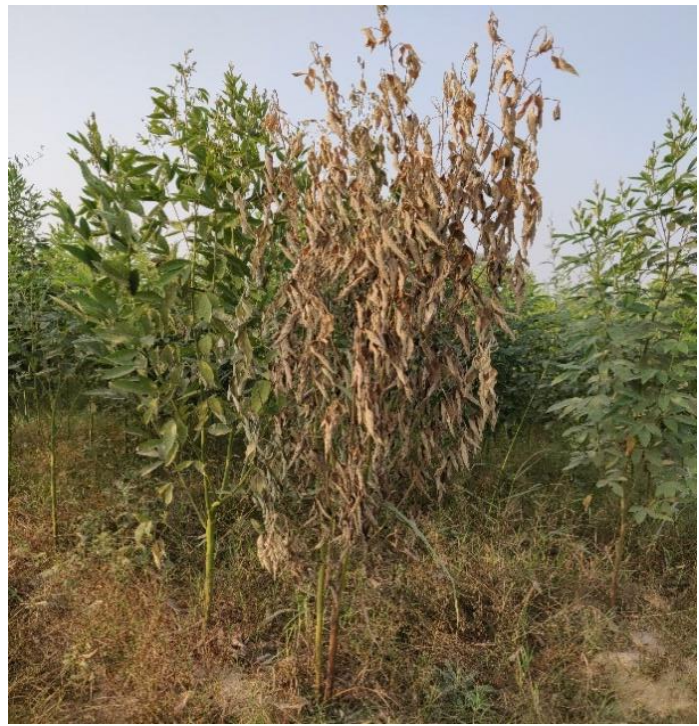

Fig.3 Growth parameters of Pigeonpea

\section{Growth Parameters}

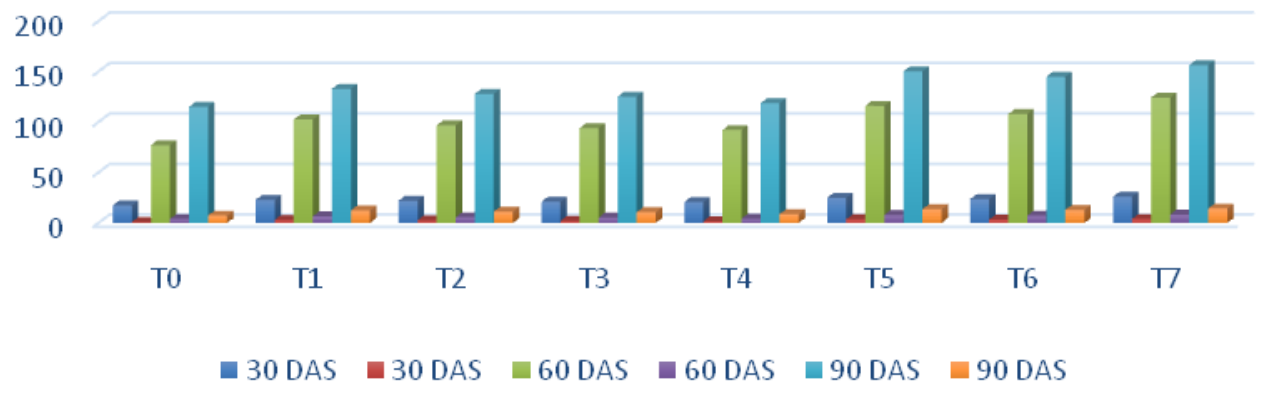


Fig.4 Effect of disease incidence

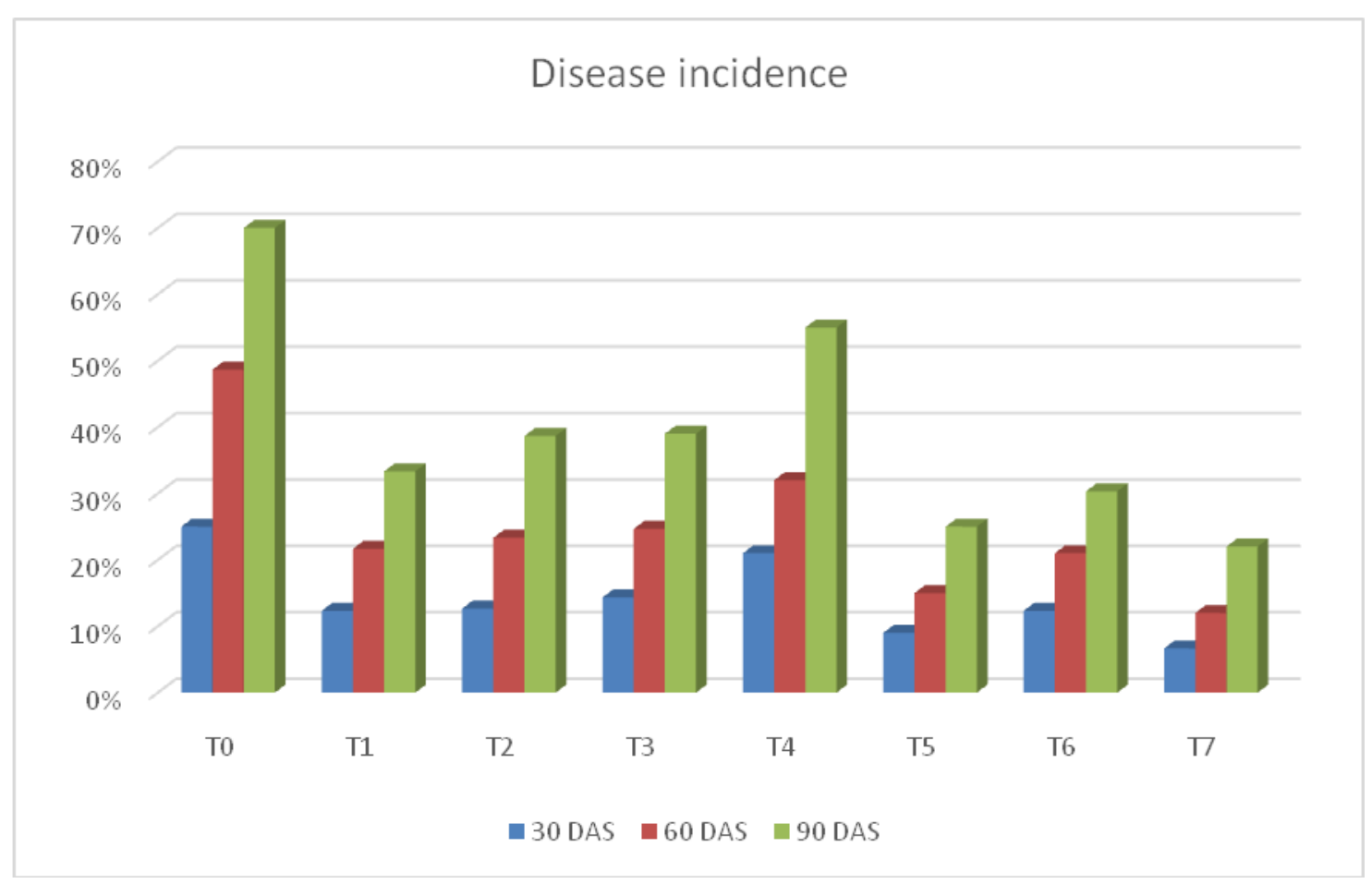

They reported that bio-agent Trichoderma viride + Neem oil cake or fungicide Bavistin + Neem oil cake were found equal in management of the disease.

The integrated disease management strategies should be chosen to maintain plant health. These strategies include minimum use of chemicals for checking pathogen population, encouragement of beneficial biological agents and use of various botanicals for reduction of pathogen population, modification of cultural practices and use of resistant varieties. These strategies help in checking the growth of pathogen and simultaneously causing no damage to the environment and non-targeted organism.

The present study concludes that Castor oil when combined with Trichoderma viride with $5 \%$ each provides maximum inhibitory effect among the selected treatments followed by Neem oil $+T$. viride $5 \%$ each against Fusarium udum. It has also shown good effects on growth parameters of Pigeonpea making it a reliable eco-friendly management option against Fusarium udum causing wilt in Pigeonpea.

\section{References}

Bagwan, N. B. (2010). Evaluation of Trichoderma compatibility with fungicides, pesticides, organic cakes and botanicals for integrated management of soil borne diseases. International journal of Plant Protection, 2(3): 206-209.

Datta, J. and Lal, N. (2013). Genetic diversity of Fusarium wilt races of Pigeonpea in major regions of India. African Crop Science Journal, 21(3): 201-211.

Hashem, M., Mohram, A. M., Zaied, A. A. and Saleh, F. E. M. (2010): Efficacy of essential oils in the control of Cumin root rot disease. Crop protection, 29(10): 1111-1117. 
Jaiswal, A. K., Tiwari, S., Faisal, M. and Shukla, H. O. (2015). Biological control of tomato wilt through soil application of bio-agent and organic amendments. Journal of Eco-friendly Agriculture 10(2): 189-190.

Javaid, B., Rana, N., Misbah. and Javed, K. (2015) Antimicrobial studies of Ricinis communis seeds extracts. International journal of scientific research and management, 5(3): 2752-2759.

Mesapogu, S., Bakshi, A., Kishore, B., Babu, S., Reddy, S., Saxena, S. and Arora, D. K. (2012). Genetic diversity and pathogenicity variability among India isolates of Fusarium udum infecting pigeonpea (Cajanus cajan (L.) Millsp). In3ernational Research Journal of Agricultural Science and Soil Science, 2(1): 051-057.

Naglot, A., Goswami, S., Rahman, I., Shimali, D. D., Kamlesh, K. Y., Gupta, V. K.,
Rabha, A. J., Gogoi, H. K. and Veer, V. (2015). Antagonistic potential of native Trichoderma viride strain against potent tea fungal pathogens in north east India. The plant pathology journal, 31(3): 278-289.

Singh, A. K.,Singh, S. S., Prakash, V., Kumar, S. and Dwivedi, S. K. (2015). Pulses production in India: Present status, bottleneck and way forward. Journal of Agrisearch, 2(2): 75-83.

Tiwari, S. and Dhar, V. (2011). Prevalence of new variants of Fusarium udum in India. Indian Phytopathology, 3(64): 243-246.

Zote, K. K., Nikam, P. S., Suryawanshi, A. P., Lakhmod, L. K., Wadje, A. G. and Kadam, T.S. (2007). Integrated management of chickpea wilt. Journal of Plant Disease Sciences, 2(2): 162163.

\section{How to cite this article:}

Kondakari Mahanthi, Shashi Tiwari and Amrita Subhadarshini. 2019. Management of Fusarium Wilt of Pigeonpea by Selected Essential Oils and T. viride. Int.J.Curr.Microbiol.App.Sci. 8(11): 596-605. doi: https://doi.org/10.20546/ijcmas.2019.811.073 